\title{
Improved Monitoring of Semi-Continuous Anaerobic Digestion of Sugarcane Waste: Effects of Increasing Organic Loading Rate on Methanogenic Community Dynamics
}

\author{
Athaydes Francisco Leite ${ }^{1}$, Leandro Janke ${ }^{2}$, Zuopeng Lv ${ }^{1}$, Hauke Harms ${ }^{1}$, \\ Hans-Hermann Richnow ${ }^{3}$ and Marcell Nikolausz ${ }^{1, *}$
}

1 Department of Environmental Microbiology, Helmholtz Centre for Environmental Research-UFZ, Permoserstrasse 15, 04318 Leipzig, Germany; E-Mails: athaydes.leite@ufz.de (A.F.L.); zuopeng.lv@ufz.de (Z.L.); hauke.harms@ufz.de (H.H.)

2 Department of Biochemical Conversion, Deutsches Biomasseforschungszentrum Gemeinnützige GmbH, Torgauerstrasse 116, 04347 Leipzig, Germany; E-Mail: leandro.janke@dbfz.de

3 Department of Isotope Biogeochemistry, Helmholtz Centre for Environmental Research-UFZ, Permoserstrasse 15,04318 Leipzig, Germany; E-Mail: hans.richnow@ufz.de

* Author to whom correspondence should be addressed; E-Mail: marcell.nikolausz@ufz.de; Tel.: +49-341-2434-566.

Academic Editor: Marianne Su-Ling Brooks

Received: 28 August 2015 / Accepted: 22 September 2015 / Published: 25 September 2015

\begin{abstract}
The anaerobic digestion of filter cake and its co-digestion with bagasse, and the effect of gradual increase of the organic loading rate (OLR) from start-up to overload were investigated. Understanding the influence of environmental and technical parameters on the development of particular methanogenic pathway in the biogas process was an important aim for the prediction and prevention of process failure. The rapid accumulation of volatile organic acids at high OLR of 3.0 to $4.0 \mathrm{~g}_{\mathrm{vs}} \cdot \mathrm{L}^{-1} \cdot \mathrm{day}^{-1}$ indicated strong process inhibition. Methanogenic community dynamics of the reactors was monitored by stable isotope composition of biogas and molecular biological analysis. A potential shift toward the aceticlastic methanogenesis was observed along with the OLR increase under stable reactor operating conditions. Reactor overloading and process failure were indicated by the tendency to return to a predominance of hydrogenotrophic methanogenesis with rising abundances of the orders Methanobacteriales and Methanomicrobiales and drop of the genus Methanosarcina abundance.
\end{abstract}


Keywords: sugarcane waste; biogas reactor overloading; methanogenic pathways; stable isotope fingerprinting; monitoring tool

\section{Introduction}

Sugarcane is widely used in Brazil for bioethanol and sugar production. Bioethanol is well established as fuel primarily in Brazil, whereas sugar supplies the national and international markets. However, the waste generated by the bioethanol/sugar industry consisting mainly of filter cake, vinasse, and bagasse is not managed adequately, since it is still rich in energy when disposed. For the treatment of these waste products, the anaerobic digestion (AD) process was chosen as a promising technology for energy recovery, since the digestate could still be used to fertilize the sugarcane fields, as discussed in our previous study [1-4].

Despite the methane potential of sugarcane waste, the use of such novel substrates in AD requires research to achieve a process of practical and economic viability. Applying a continuous feeding biogas process along the entire year is a challenge due to the temporal availability of the substrate during approximately 200 operating days of the Brazilian bioethanol/sugar industry. A rapid start-up of the biogas process for more productivity reaching high levels of OLR at the beginning of the operation season may be the solution. Furthermore, the organic loading rate (OLR) is a factor of interest as it determines how much substrate can be treated and converted into biogas per time and reactor volume. However, at high OLR there is a risk of acidification by overloading, potentially followed by process failure. The tightrope walk between exploiting the reactor potential and maintaining a stable process requires cost effective monitoring which allows predicting and assessing process instabilities/failure particularly when the feeding regime is changed. It has been shown that stable isotope fingerprinting of the produced biogas can provide information about the most sensitive functional guild in the $\mathrm{AD}$, the methanogens [5].

In $\mathrm{AD}$ the organic matter degradation into biogas proceeds in four major steps, i.e., hydrolysis, acidogenesis, acetogenesis, and methanogenesis, which are carried out by the complex consortia of various bacteria and methanogenic archaea [6]. Methanogenesis, as the terminal phase for methane production, to which two major pathways (aceticlastic and hydrogenotrophic methanogenesis) contribute, is a major target for biogas process optimization [7].

Acetate, $\mathrm{H}_{2}$, and $\mathrm{CO}_{2}$ (or formate) are the products of the digestion of macromolecules by hydrolytic, acidogenic, and acetogenic bacteria. Aceticlastic methanogens convert acetate into methane and carbon dioxide, whereas hydrogenotrophic methanogens catalyze the conversion of $\mathrm{H}_{2}$ and $\mathrm{CO}_{2}$ (or formate) to methane. In a stable AD process these complex microbial consortia cooperate and self-regulate their abundances and activities. However, overproduction of organic acids by the bacterial community, e.g., triggered by substrate overload, may overexert the downstream consumption and result in drastic acidification which inhibits the methane production [8]. Thus, to establish and optimize a biogas process with novel substrates such as waste products from the bioethanol/sugar industry, it is essential to study the propensity for acidification and its effect on the methanogenic communities. 
Several research studies using different substrates have assessed the microbial diversity in laboratory- and large-scale biogas reactor [9-11] and the effect of reactor parameters such as organic acid accumulation on the methanogenic diversity and pathway dominance [12-14]. However, to our best knowledge, the effect of acidification by overloading of biogas reactors fed with sugarcane waste has not been investigated. Furthermore, it is known that the susceptibility of AD to overloading depends on the substrate, reactor type, and temperature, thus motivating the present investigation with a novel substrate.

The assessment of the methanogenic community in biogas reactors requires appropriate methods. Variations of the methanogenic community can be analyzed by molecular techniques $[15,16]$, whereas analysis of the biogas isotope composition provides information about the relative contributions of the methanogenic pathways [5,17-19]. While molecular biological analyses appear very time-consuming and costly for routine process monitoring, biogas isotope composition appears to be a promising monitoring parameter for industrial biogas processes [20].

Laboratory-scale, semi-continuously-fed, stirred digesters were established to observe the changes of the activity of methanogens as a function of reactor acidification triggered by overloading. Two parallel reactors with mono-digestion of filter cake as substrate, and two other parallel reactors with co-digestion of filter cake and bagasse were monitored by molecular and isotopic techniques to determine the contributions of the methanogenic pathways. Statistical analyses served to correlate isotope signatures and community structures.

\section{Results and Discussion}

\subsection{Biogas Reactor Performance}

In Table 1 the technical parameters and reactor performance during the eight phases of operation are shown. An average value was calculated for each of the two reactor pairs performing mono- and co-digestion. Due to the high volatile organic acids (VOA) concentration $\left(2.45 \mathrm{~g} \cdot \mathrm{L}^{-1}\right)$ of the digestate mixture used as inoculum, an acclimation of 10 days was required for degradation of the remaining organic matter from the previous reactors. The OLR increased from 0.5 to $4.0 \mathrm{gvs}_{\mathrm{vs}} \cdot \mathrm{L}^{-1} \cdot \mathrm{day}^{-1}$ within nine weeks. As a consequence, the hydraulic retention time (HRT) decreased from 36 to 7 and from 37 to 12 days for the mono- and co-digestion reactors, respectively. Along the experiment until Phase 5, the biogas yield was lower for mono- than for co-digestion, whereas the methane content, in mono-digestion reactors was higher. After exceeding the OLR of 2.5 (Phase 5) and $3.0 \mathrm{~g}_{\mathrm{vs}} \cdot \mathrm{L}^{-1} \cdot \mathrm{day}^{-1}$ (Phase 6) for co- and mono-digestion, respectively, the biogas yield decreased drastically. In the co-digestion reactors, the biogas production was inhibited earlier because the $\mathrm{pH}$ and the buffering capacity were lowered already in Phase 6 . In the following phases, the buffer capacity was insufficient to neutralize the VOA accumulation. The acidification led to decreased biogas yield followed by process failure in both digestion set-ups. Reactor overload and imbalance were already noticed in Phase 6, when the propionate-to-acetate ratios rose from 0.043 to $1.434(33 \times)$ and 0.037 to $1.999(54 \times)$ for mono- and co-digestion, respectively. The results from this phase for mono-digestion were consistent with some other studies, thus confirming that the overload effect is seen earlier from the propionate-to-acetate ratio than from changes in $\mathrm{pH}$ or in biogas yield [12,14,21]. Prochazka, et al. [22] 
reported that low ammonium nitrogen $\left(\mathrm{NH}_{4}-\mathrm{N}\right)$ concentration $\left(0.5 \mathrm{~g} \cdot \mathrm{L}^{-1}\right)$ caused low methane yield, loss of biomass and loss of aceticlastic methanogenic activity, and further presented lower buffer capacity and less stable $\mathrm{pH}$. However, this statement does not corroborate our results until Phase 5, indicating that these findings were circumstantial, i.e., depending on the substrate and microbial adaptation. Although the low $\mathrm{NH}_{4}-\mathrm{N}$ concentration during mono-digestion in Phase 6 did not influence negatively the methane yield, foaming was observed in both parallel reactors, which necessitated liquid volume reduction for mono-digestion. The foaming can be ascribed to non-degraded soluble organics, which result in the surface tension reduction of reactor content [23]. At high volatile organic acids per total inorganic carbonate buffer (VOA/TIC) values $\left(3.1 \mathrm{gvOA} \cdot \mathrm{g}_{\mathrm{CaCO}}{ }^{-1}\right)$ in Phase 7 , the total- (TS) and volatile solids (VS) values also increased due to the lack of further degradation of the organic matter. This indicated that not just the methanogenesis, but the whole process was inhibited eventually.

\subsection{Methanogenic Community Dynamics}

The diversity and structure of the methanogenic communities from the mono- and co-digestion were investigated by terminal restriction fragment length polymorphism (T-RFLP) fingerprinting of the mcrA/mrtA gene (Figure 1) and further validated by sequence analysis of clone libraries (Supplementary Table S1). Immediately before the first feeding on day 10, the reactors displayed similar mcrA/mrtA profiles for both reactor types, but a slight difference in the relative T-RF abundances was observed, indicating distinct acclimatization of the inoculum mixture. In Phase 1, the strictly aceticlastic genus Methanosaeta and the versatile genus Methanosarcina were more abundant in mono- than in co-digestion set-ups, whereas the strictly hydrogenotrophic genus Methanoculleus was more predominant in the co-digestion reactors. In both digestions, the abundance of Methanosarcina increased gradually from Phase 2 to Phase 6, reaching a proportion of approximately $80 \%$. Methanosaeta was not detected after the acetic acid concentration started to increase in the process in Phase 4. The high affinity of Methanosaeta for acetate is a competitive advantage over Methanosarcina at low acetic acid concentrations [24], but at higher concentrations Methanosarcina is outcompeting Methanosaeta. Our observation of Methanosaeta at low acetic acid concentration is consistent with the findings of other studies [12,25,26]. To our surprise, at very high acetic acid concentrations during the Phase 7 and Phase 8 of mono-digestion, Methanosaeta was detected again, whereas the abundance of Methanosarcina dropped. Chen and He [27] also demonstrated competitiveness of Methanosaeta with Methanosarcina at high acetate levels. In the co-digestion reactors Methanobacterium predominated mainly in Phases 7 and 8. Sequences affiliated to the hydrogenotrophic genus Methanoregula were relatively abundant in the last phases of the experiment, when the propionate-to-acetate ratio drastically increased and the $\mathrm{pH}$ decreased. According to Yashiro, et al. [28] the genus Methanoregula includes acid-tolerant strains. 
Table 1. Major reactor parameters along the eight phases of the experiment set-up.

\begin{tabular}{|c|c|c|c|c|c|c|c|c|c|c|c|c|c|c|c|c|}
\hline \multirow{3}{*}{ Reactor' Parameters } & \multicolumn{2}{|c|}{$\begin{array}{c}\text { Phase } 1 \\
\text { (sampling Day: 19) }\end{array}$} & \multicolumn{2}{|c|}{$\begin{array}{c}\text { Phase } 2 \\
\text { (sampling day: 26) }\end{array}$} & \multicolumn{2}{|c|}{$\begin{array}{c}\text { Phase } 3 \\
\text { (sampling day: 33) }\end{array}$} & \multicolumn{2}{|c|}{$\begin{array}{c}\text { Phase } 4 \\
\text { (sampling day: 40) }\end{array}$} & \multicolumn{2}{|c|}{$\begin{array}{c}\text { Phase } 5 \\
\text { (sampling day: 55) }\end{array}$} & \multicolumn{2}{|c|}{$\begin{array}{c}\text { Phase } 6 \\
\text { (sampling day: 61) }\end{array}$} & \multicolumn{2}{|c|}{$\begin{array}{c}\text { Phase } 7 \\
\text { (sampling day: } 68 \text { ) }\end{array}$} & \multicolumn{2}{|c|}{$\begin{array}{c}\text { Phase } 8 \\
\text { (sampling day: } 75 \text { ) }\end{array}$} \\
\hline & Mono- & Co- & Mono- & Co- & Mono- & Co- & Mono- & Co- & Mono- & Co- & Mono- & Co- & Mono- & Co- & Mono- & Co- \\
\hline & \multicolumn{2}{|c|}{ Digestion } & \multicolumn{2}{|c|}{ Digestion } & \multicolumn{2}{|c|}{ Digestion } & \multicolumn{2}{|c|}{ Digestion } & \multicolumn{2}{|c|}{ Digestion } & \multicolumn{2}{|c|}{ Digestion } & \multicolumn{2}{|c|}{ Digestion } & \multicolumn{2}{|c|}{ Digestion } \\
\hline $\mathrm{CH}_{4} \S(\%)$ & 57.7 & 55.6 & 57.4 & 56.6 & 60.3 & 53.9 & 57.8 & 54.9 & 61.3 & 54.9 & 61.1 & na & na & na & na & na \\
\hline $\mathrm{CO}_{2} \S(\%)$ & 42.3 & 44.4 & 42.6 & 43.4 & 39.7 & 46.1 & 42.2 & 45.1 & 38.7 & 45.1 & 38.9 & na & na & na & na & na \\
\hline Acetic acid $\left(\mathrm{mg} \cdot \mathrm{L}^{-1}\right)$ & 55.7 & 37.3 & 26.7 & 25.4 & 46.1 & 69.6 & 160.3 & 120.5 & 240.6 & 155.6 & 145.1 & 141.9 & 1003.0 & 914.2 & 1370.0 & 1334.1 \\
\hline$n$-Butyric acid $\left(\mathrm{mg} \cdot \mathrm{L}^{-1}\right)$ & 4.7 & 2.5 & 3.1 & 2.0 & 2.2 & 1.8 & 19.5 & 12.1 & 5.3 & 1.8 & 26.0 & 6.7 & 428.9 & 403.3 & 1144.8 & 1193.0 \\
\hline $\operatorname{VOA}\left(\mathrm{g} \cdot \mathrm{L}^{-1}\right)$ & 0.8 & 0.8 & 0.6 & 0.7 & 0.6 & 0.6 & 0.5 & 0.5 & 1.0 & 0.8 & 0.6 & 0.6 & 2.2 & 2.1 & na & na \\
\hline $\mathrm{VOA} / \mathrm{TIC}\left(\mathrm{g}_{\mathrm{VOA}} \cdot \mathrm{g}_{\mathrm{CaCO}^{-1}}{ }^{-1}\right)$ & 0.2 & 0.2 & 0.2 & 0.1 & 0.2 & 0.2 & 0.2 & 0.2 & 0.2 & 0.2 & 0.7 & 0.6 & 3.1 & 3.1 & na & na \\
\hline $\mathrm{pH}^{*}$ & 7.5 & 7.5 & 7.4 & 7.3 & 7.5 & 7.5 & 7.2 & 7.1 & 7.2 & 6.9 & 7.0 & 6.5 & 6.3 & 5.7 & 5.4 & 5.2 \\
\hline $\mathrm{NH}_{4}-\mathrm{N}\left(\mathrm{g} \cdot \mathrm{L}^{-1}\right)$ & 1.0 & 1.1 & 0.8 & 0.8 & 0.6 & 0.9 & 0.5 & 0.5 & 0.3 & 0.3 & 0.1 & 0.1 & 0.2 & 0.1 & 0.1 & 0.2 \\
\hline TS (\%) & 3.1 & 2.9 & 2.7 & 2.6 & 2.5 & 2.7 & 2.3 & 2.8 & 2.1 & 2.3 & 2.1 & 2.1 & 5.6 & na & 6.9 & 7.6 \\
\hline
\end{tabular}

* Only for these parameters an average of all measurements during each specific Phase was done, since these parameters were analyzed almost every day; ${ }^{\S}$ Trace gases were not detected in our measurements with the applied technique, therefore we rounded our $\mathrm{CH}_{4}$ and $\mathrm{CO}_{2}$ values to $100 \%$; "sampling day" corresponds to the last Phase day, when the samples were analyzed; "na" refers to not analysed due to technical operation problems: the very low biogas production on the last two phases hindered the GC measurement for gas composition; the low $\mathrm{pH}$ values detected on the last phase hindered the titration of sample for measuring VOA and VOA/TIC; and the TS and VS measurement was hindered by technical mistake while handling the samples. 

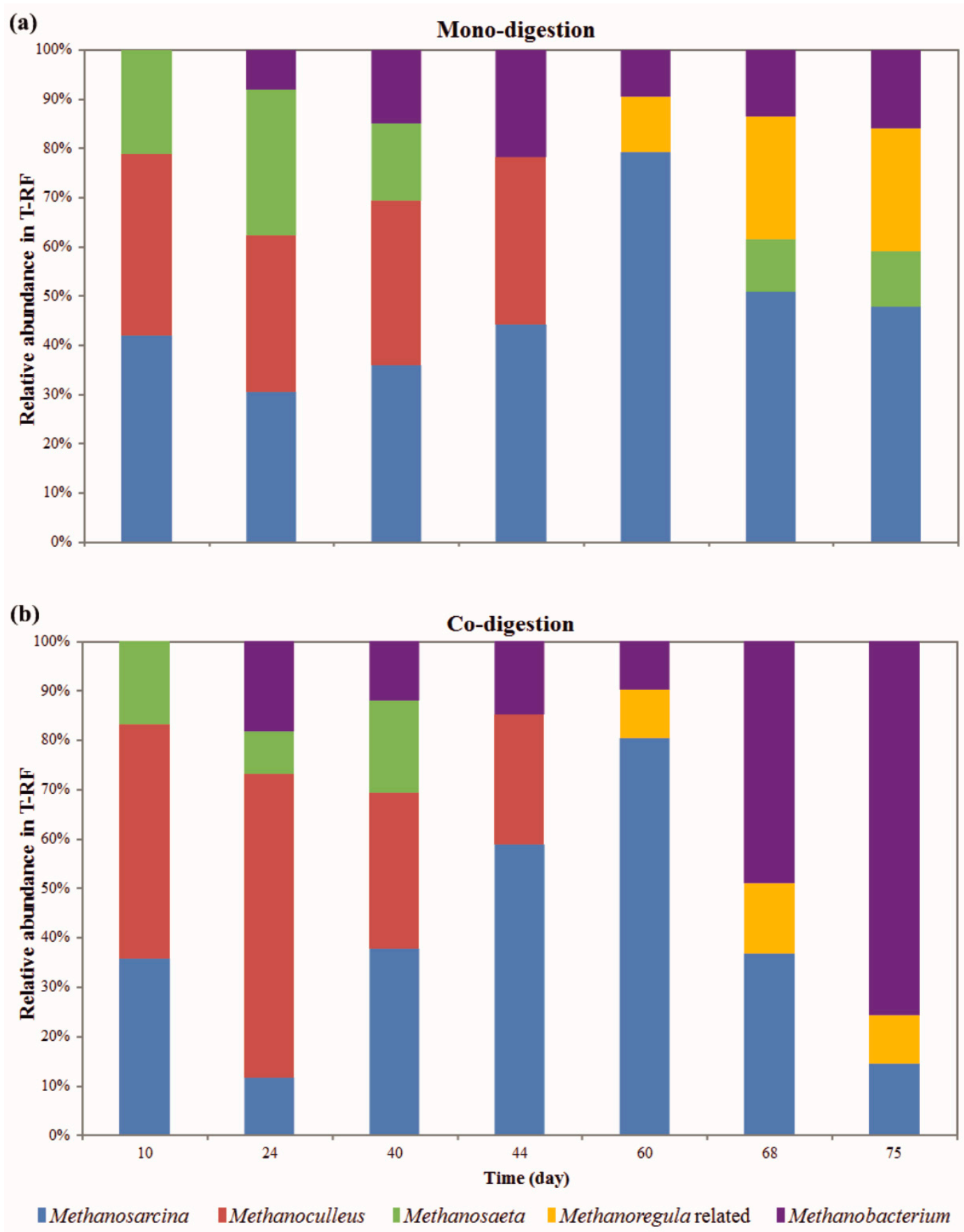

Figure 1. Methanogenic community dynamics in the mono- (a) and co-digestion (b) reactor. The relative $\mathrm{T}-\mathrm{RF}$ abundance of methanogens in the digestate samples are given as function of experiment time. For each of the parallel reactors in the specific digestion set-up, two samples were analyzed, that in total four samples were analyzed for each, mono- and co-digestion. All samples belonging to the same digestion set-up had similar methanogenic community based on the relative T-RF abundances. Therefore, each bar on the graphic represents the T-RFLP profile calculated by the average of the four analyzed samples in each digestion set-up. The supporting clone libraries and sequence analysis of the selected clones allowed the taxonomic affiliation of the T-RFs from the community T-RFLP profiles of the complex reactor samples. 


\subsection{Isotopic Changes of the Produced Biogas}

Carbon-stable isotope compositions of filter cake and bagasse samples were analyzed since they influence the final isotope composition of the produced methane [5]. Filter cake and bagasse had isotope signatures of $-14.30 \%$ and $-13.64 \% \delta^{13} \mathrm{C}$, respectively, which are in the typical range for $\mathrm{C} 4$ plants $\left(\delta^{13} \mathrm{C}\right.$ values between $-12 \%$ and $-16 \%$ ) [29].

The gradual overload of the mono- and co-digestion reactors resulted in process changes that were monitored via the isotope composition of the biogas in terms of $\delta^{13} \mathrm{C}_{\mathrm{CH} 4}, \delta^{13} \mathrm{CCO}_{\mathrm{CO}}$, and $\delta^{2} \mathrm{H}_{\mathrm{CH} 4}$ (Figure 2). Both digestion set-ups had very similar dynamics. The $\delta^{13} \mathrm{C}_{\mathrm{CH} 4}$ became enriched from $-52 \%$ to about $-32 \%$ along the gradual OLR increase until Phase 5 at $2.5 \mathrm{gvs}_{\mathrm{vs}} \cdot \mathrm{L}^{-1} \cdot \mathrm{day}^{-1}$ (Figure 2a). Following, the Phase 6 had similar isotope values as the previous phase. This stationary isotope signature around $-32 \%$ is consistent with former studies that found similar isotope fractionation of biogas samples from continuous stirred tank reactors (CSTRs) fed with C4 plant maize silage [5,19]. The inhibition of biogas production in co-digestion in Phase 6 also coincided with the isotopic depletion of the methane associated with slightly lighter $\delta^{13} \mathrm{C}_{\mathrm{CH} 4}$ values. In the last two phases of the experiment, when the process was clearly inhibited, depletion of $\delta^{13} \mathrm{C}_{\mathrm{CH}} 4$ values was observed.

The $\delta^{13} \mathrm{C}$ of carbon dioxide in the produced biogas in the mono- and co-digestion presented also similar trends (Figure 2b) with an enrichment from 4\%o to about 15\%. However, only in Phase 6 the tendency between both digestion set-ups differed. In this case, the biogas production inhibition in co-digestion may have resulted in abrupt $\delta^{13} \mathrm{C}_{\mathrm{CO} 2}$ depletion. Phase 7 had the most enriched $\delta^{13} \mathrm{C}_{\mathrm{CO} 2}$ composition, followed by drastic depletion in ${ }^{13} \mathrm{C}$ values in Phase 8 . However, the observed isotope effect is at certain extent due to the decreasing $\mathrm{pH}$ and the associated fast degassing of the $\mathrm{CO}_{2}$ from the bicarbonate in the liquid.

The hydrogen isotope composition of methane $\left(\delta^{2} \mathrm{H}_{\mathrm{CH} 4}\right)$ in the mono- and co-digestion shows similar trends (Figure 2c). The hydrogen isotope compositions showed an opposite tendency to carbon isotope composition regarding enrichment and depletion periods. After the feeding regime has stated at Phase 1 the isotope values depleted from around $-327 \%$ to $-342 \%$ at the end of the stable operation phases. In the final phases, $\delta^{2} \mathrm{H}_{\mathrm{CH} 4}$ enriched to about $-322 \%$ when OLR drove the methanogenic process to collapse. 


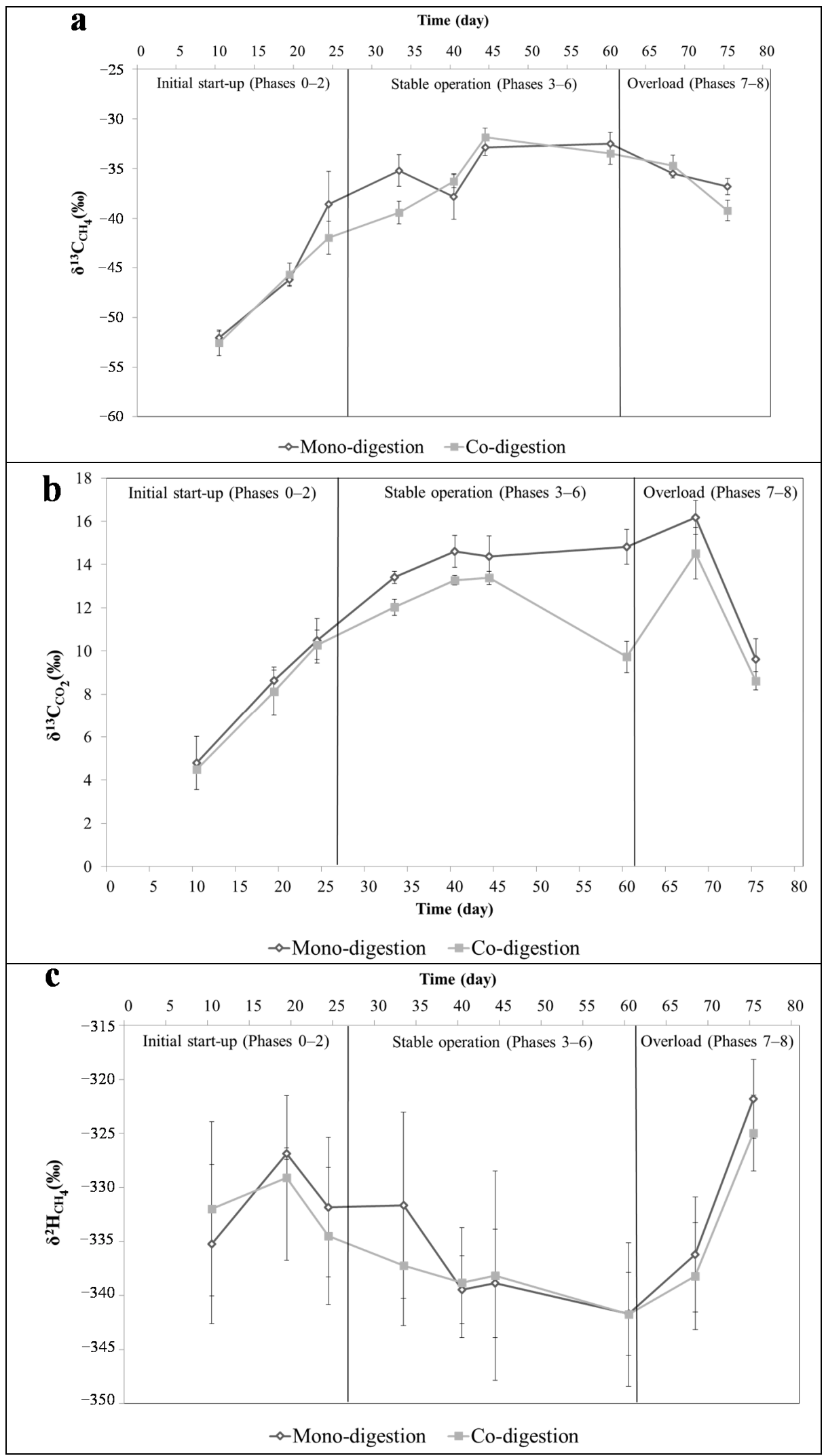

Figure 2. Isotopic dynamics of $\delta^{13} \mathrm{C}_{\mathrm{CH} 4}(\mathbf{a}) ; \delta^{13} \mathrm{C}_{\mathrm{CO} 2}(\mathbf{b})$; and $\delta^{2} \mathrm{H}_{\mathrm{CH} 4}(\mathbf{c})$ along gradual OLR increase in biogas reactors fed with sugarcane waste products. Isotope data of $\mathrm{CO}_{2}$ during the last overload phase contains data uncorrected regarding the $\mathrm{pH}$ shift induced degassing. 


\subsection{Methanogenic Pathways}

The apparent fractionation factor $(\alpha \mathrm{C})$ calculated based on $\delta^{13} \mathrm{C}_{\mathrm{CH} 4}$ and $\delta^{13} \mathrm{C}_{\mathrm{CO} 2}$ composition as previously described [30-32] was used to identify a predominance of hydrogenotrophic and aceticlastic methanogenesis (Figure 3a). An intermediate $\alpha \mathrm{C}$ value ranging between 1.065 (>for hydrogenotrophic) and 1.025 (< for aceticlastic) was found in our experiment, indicating that the methane produced during increasing OLR was derived similarly from both methanogenic pathways. This agrees with the broad spectrum of methanogenic genera (Figure 1) which included the versatile genus Methanosarcina, the strictly aceticlastic genus Methanosaeta and the strictly hydrogenotrophic order Methanomicrobiales (Methanoculleus and Methanoregula-related microorganisms) and the genus Methanobacterium. However, the high $\alpha \mathrm{C}$ values 1.060 and 1.056 at the beginning of the experiment, in Phase 0 (at day 10 just before the first feeding) and Phase 1, respectively, indicated a predominance of hydrogenotrophic methanogenesis, suggesting that Methanosarcina was using this pathway together with Methanoculleus and Methanobacterium. The substrates from other AD processes in the mixture of digestate inoculated in our reactors may have also contributed to the initial isotope composition. Along the experiment, the relative abundance of Methanosarcina gradually increased and may have slightly shifted the methanogenesis from the hydrogenotrophic towards the aceticlastic pathway until the OLR of $3.0 \mathrm{gvs}_{\mathrm{v}} \cdot \mathrm{L}^{-1} \cdot \mathrm{day}^{-1}$ was reached. In this case, the composition of sugarcane waste and the added water favored a tendency towards aceticlastic methanogenesis, though the strictly aceticlastic genus Methanosaeta was no longer abundant after Phase 4 in both digestion set-ups. However, in case of mono-digestion in the inhibition-characterized Phases 7 and 8, sequences affiliated with the genus Methanosaeta were detected again. A similar finding was described by Schmidt, et al. [33] who observed that decreasing HRT may favor the genus Methanosaeta under certain conditions. Nikolausz, et al. [5] described that more depleted $\delta^{13} \mathrm{C}_{\mathrm{CH} 4}$ values in biogas reactors potentially indicate a shift toward the dominance of hydrogenotrophic methanogenesis. This observation was also supported by our results. Since the first feeding with the sugarcane waste products Methanobacterium became abundant with minor changes along mono-digestion and with increase in dominance during overload of co-digestion reactors. This was shown by the increase of the $\alpha \mathrm{C}$ values at reactor overload, which also indicated a shift towards hydrogenotrophic methanogenesis. In addition, the relative abundance of the other hydrogenotrophic taxon related to the genus Methanoregula also increased during reactor overload in both digestion set-ups.

The combination plot of $\delta^{13} \mathrm{C}_{\mathrm{CH} 4}$ and $\delta^{2} \mathrm{H}_{\mathrm{CH} 4}$ as function of increasing ORL is shown in Figure $3 \mathrm{~b}$, where the dotted, dashed, and lined hulls represent the beginning, middle, and end of the experiment, respectively. Phases 0 and 1 are represented in the dotted hull with higher $\alpha \mathrm{C}$ values as described earlier. The dashed hull area is covering most of the phases (from Phase 2 to Phase 7), which had similar ranges and trends of $\alpha \mathrm{C}$ values for mono-digestion (1.049-1.055) and co-digestion (1.045-1.055). Samples from Phase 8 are grouped into the lined hull, representing the period when the mono- and co-digestion reactors were overloaded, imbalances were clearly observed and less depleted $\delta \mathrm{D}$ values were measured. The isotope effect associated with aceticlastic methanogenesis is significantly larger in case of hydrogen derived from the water, but it affects only one out of four hydrogen atoms of the methane, while the other three atoms are influenced by the $\delta \mathrm{D}$ of the organic matter. In natural environments aceticlastic methanogenesis results in more depleted $\delta \mathrm{D}$ values of 
methane, which is in agreement with our data where depleted values were observed during the stable reactor operating conditions and explained by the predominance of Methanosarcina.

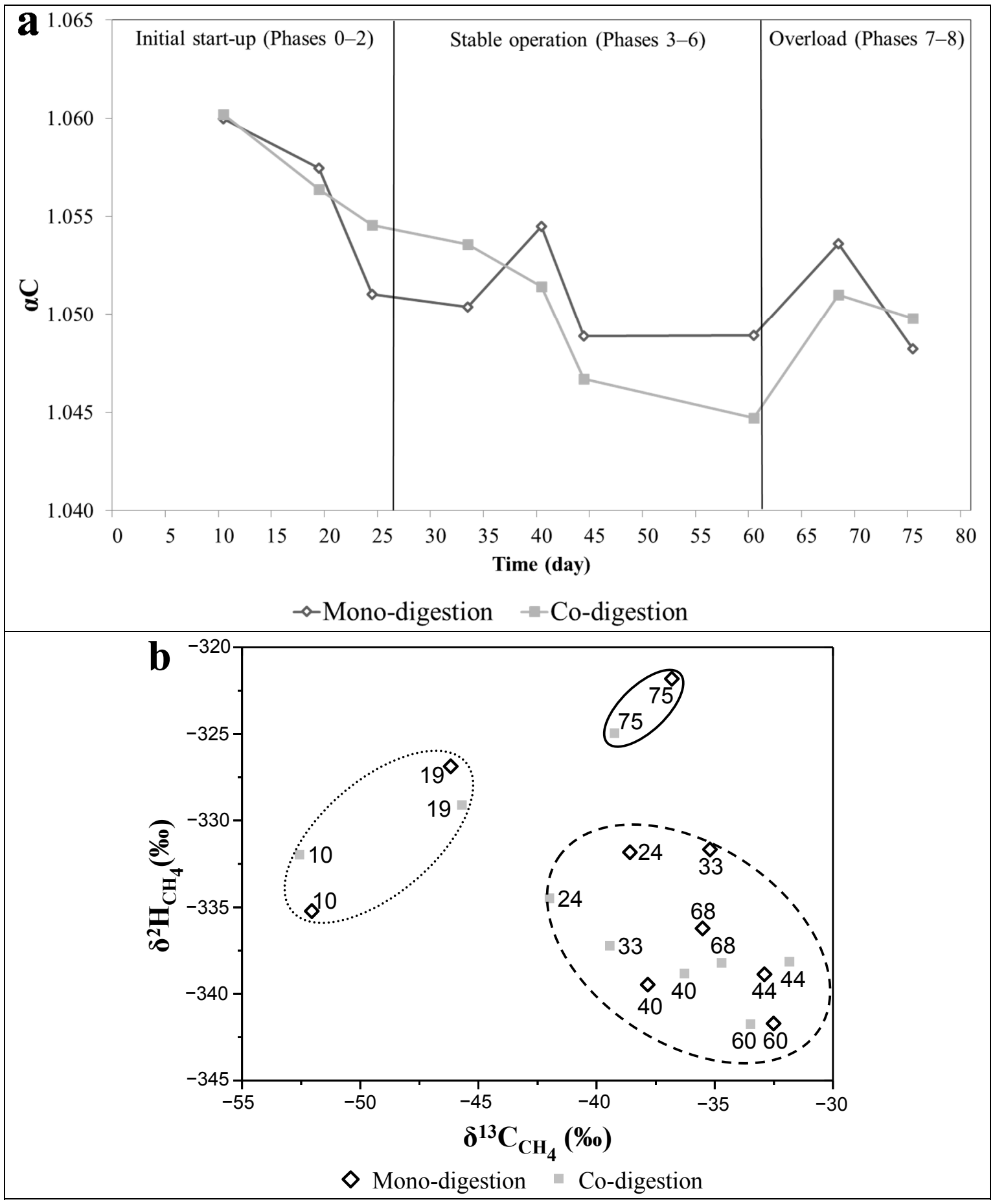

Figure 3. Characterization of the potential predominant methanogenic pathway along gradual OLR increase in biogas reactors fed with sugarcane waste products in mono- and co-digestion. In diagram (a) the dynamic shift of $\alpha \mathrm{C}$ values are shown, while diagram (b) presents the correlation of $\delta^{2} \mathrm{HCH}_{4}$ and $\delta^{13} \mathrm{C}_{\mathrm{CH} 4}$; In (b) the dotted, dashed and lined hulls represent the beginning, middle, and end of the experiment, respectively. The numbers in the graphic indicate the experiment day. 
In Figure 4 the correlation between the T-RFLP profile dynamics and the isotope composition of biogas is shown in a non-metric multidimensional scaling (NMDS) plot. The methanogenic pathway shift can be viewed in the NMDS plot as shifts of T-RFLP profile clusters (dashed hulls) during the different phases of the ORL increase. The methanogenic community most significantly correlates with the isotopic fractionation of $\delta^{13} \mathrm{C}_{\mathrm{CH} 4}$ as indicated by the vector converted to the larger grey arrow in the NMDS plot. The reactor overload in Phases 7 and 8 for mono-digestion was characterized by a strong correlation of the hydrogenotrophic taxon related to the genus Methanoregula and less depleted isotopic values of $\delta^{13} \mathrm{C}_{\mathrm{CH}} 4$ and $\delta^{13} \mathrm{C}_{\mathrm{CO} 2}$, whereas for co-digestion it was characterized by a significant correlation of the strict hydrogenotrophic genus Methanobacterium and $\delta^{2} \mathrm{H}_{\mathrm{CH} 4}$. This corroborates the increase of the $\alpha \mathrm{C}$ values for both digestion set-ups at reactor overload in Phase 7 indicating the shift towards hydrogenotrophic methanogenesis and higher $\alpha \mathrm{C}$ values of co-digestion compared to mono-digestion at the Phase 8, when the relative abundance of Methanobacterium was around 75\%.

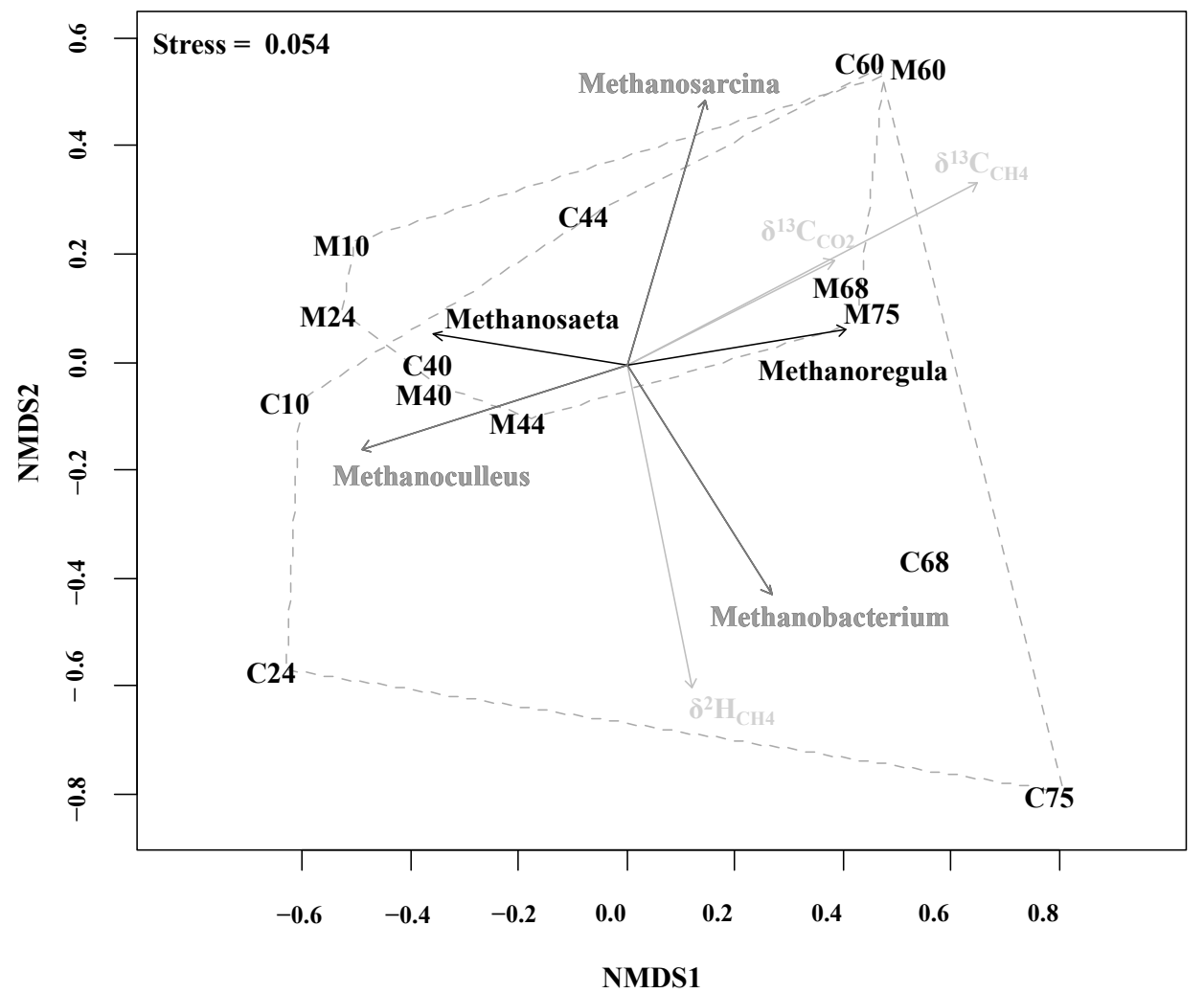

Figure 4. NMDS analysis plot for correlating the T-RFLP profile of methanogens with the isotope composition of produced biogas. The smaller and bigger hull in the diagram represents the mono- and co-digestion in several sampling time, respectively. The letter $\mathrm{M}$ stands for mono-digestion and $\mathrm{C}$ for co-digestion set-up and the following numbers correspond to the sampling day. The dim grey and black arrows indicate the highly significant $(p<0.001)$ and significant $(p<0.05)$ correlations, respectively. Grey arrows indicate the correlation vectors of community differences and the isotope composition at lower significance $(p<0.5)$. Monte-Carlo permutation was used to test the significance against 999 random data sets. The direction of the arrows show the correspondence to the community structures and the length of the arrow indicate the strength of the correlation with the ordination axis. 


\section{Experimental Section}

\subsection{Biogas Reactors, Operation and Analytical Methods}

The experiment was carried out in four CSTRs under mesophilic conditions at $38{ }^{\circ} \mathrm{C}$. In order to provide a diverse microbial start-up community as inoculum, each reactor was inoculated with a mixture of digestates from several CSTRs, which had been fed daily with either maize silage, dried distillers grains with soluble (DDGS), straw or chicken manure. In our experiment, filter cake and bagasse, two solid waste products from the bioethanol industry (Goiás, Brazil), were used as substrate. Bagasse was cut to $1 \mathrm{~mm}$ pieces by milling to increase the accessible surface area and to facilitate reactor feeding and stirring. The TS and VS were $28 \%$ and $17 \%$ for filter cake and $57 \%$ and $55 \%$ for bagasse, respectively. Mono-digestion was performed with filter cake, whereas co-digestion reactors were fed at a substrate ratio of $70 \%$ filter cake and $30 \%$ bagasse (based on fresh mass), corresponding to a VS-based filter cake to bagasse ratio of 1:0.74. All four reactors were fed every day according to the digestion set-up.

Table 2 shows further technical parameters of the operation. The experiment was divided into eight phases according to the gradual increase of the OLR. Biogas production was monitored, by counting biogas bubbles in a liquid-filled pipe via digital imaging and size recognition [34]. Biogas composition was measured with a thermal conductivity detector Chrompack Micro GC CP-2002P (Middelburg, The Nederland). The TS and VS, the $\mathrm{pH}$ values, the $\mathrm{NH}_{4}-\mathrm{N}$ concentration, acetate, propionate, and $n$-butyrate were determined as described previously by Leite, et al. [1]. The total VOA concentration and the VOA/TIC were analyzed as described earlier by Ziganshin, et al. [35].

\subsection{Methanogenic Community Analysis}

Duplicate digestate samples were collected in 2-mL test tubes and immediately stored at $-20{ }^{\circ} \mathrm{C}$ for further analysis. Total DNA isolation was carried out using NucleoSpin ${ }^{\circledR}$ Soil kit (Macherey-Nagel, Düren, Germany). Methanogen-specific methyl coenzyme-M reductase ( $m c r A$ ) gene fragments were amplified by polymerase chain reaction (PCR) using the forward primer mlas and the reverse primer mcrA-rev labeled with 6-carboxyfluorescein (FAM) for T-RFLP analyses. Non-labeled primers were used for molecular cloning and sequencing as in a previous study [5]. Further, T-RFLP screening and partial sequencing of purified PCR products were performed as described by Nikolausz, et al. [5]. The BLASTN and BLASTX tools were used to search for similar sequences in public databases. The $m c r A / m r t A$ gene sequences obtained in this study were deposited in the European Bioinformatics Institute (EMBL-EBI) database under the accession numbers LN847074-LN847091. The NMDS analyses were conducted as described by Sträuber, et al. [36]. 
Table 2. Technical parameters during the experiment set-up of the mono- and co-digestion of filter cake and bagasse.

\begin{tabular}{|c|c|c|c|c|c|c|c|c|c|c|c|c|c|c|c|c|}
\hline \multirow{3}{*}{ Set-up-Technical Parameters } & \multicolumn{2}{|c|}{ Phase 1} & \multicolumn{2}{|c|}{ Phase 2} & \multicolumn{2}{|c|}{ Phase 3} & \multicolumn{2}{|c|}{ Phase 4} & \multicolumn{2}{|c|}{ Phase 5} & \multicolumn{2}{|c|}{ Phase 6} & \multicolumn{2}{|c|}{ Phase 7} & \multicolumn{2}{|c|}{ Phase 8} \\
\hline & Mono- & Co- & Mono- & Co- & Mono & Co- & Mono- & Co- & Mono- & Co- & Mono- & Co- & Mono- & Co- & Mono- & Co- \\
\hline & \multicolumn{2}{|c|}{ Digestion } & \multicolumn{2}{|c|}{ Digestion } & \multicolumn{2}{|c|}{ Digestion } & \multicolumn{2}{|c|}{ Digestion } & \multicolumn{2}{|c|}{ Digestion } & \multicolumn{2}{|c|}{ Digestion } & \multicolumn{2}{|c|}{ Digestion } & \multicolumn{2}{|c|}{ Digestion } \\
\hline Experiment phase (day) & \multicolumn{2}{|c|}{$11-19$} & \multicolumn{2}{|c|}{$20-26$} & \multicolumn{2}{|c|}{$27-33$} & \multicolumn{2}{|c|}{$34-40$} & \multicolumn{2}{|c|}{$41-55$} & \multicolumn{2}{|c|}{$56-61$} & \multicolumn{2}{|c|}{$62-68$} & \multicolumn{2}{|c|}{$69-75$} \\
\hline Substrate $\left(g_{\text {fresh mass }}\right)$ & 2.4 & 1.5 & 4.9 & 3.0 & 7.3 & 4.5 & 9.7 & 6.0 & 12.2 & 7.5 & 14.6 & 9.0 & 10.7 & 10.5 & 12.2 & 12.0 \\
\hline Water mixed with substrate $(\mathrm{mL})$ & \multicolumn{2}{|c|}{20} & \multicolumn{2}{|c|}{25} & \multicolumn{2}{|c|}{30} & \multicolumn{2}{|c|}{35} & \multicolumn{2}{|c|}{45} & \multicolumn{2}{|c|}{45} & \multicolumn{2}{|c|}{50} & \multicolumn{2}{|c|}{55} \\
\hline Working volume (L) & \multicolumn{2}{|c|}{0.8} & \multicolumn{2}{|c|}{0.8} & \multicolumn{2}{|c|}{0.8} & 0 . & & 0. & & 0 . & & 0.5 & 0.8 & 0.5 & 0.8 \\
\hline $\operatorname{VS}\left(\mathrm{g} \cdot \mathrm{day}^{-1}\right)$ & 0 . & & 0 . & & & & 1. & & 2. & & 2 & & 1.8 & 2.8 & 2.0 & 3.2 \\
\hline OLR $\left(g_{v S} \cdot L^{-1} \cdot\right.$ day $\left.^{-1}\right)$ & 0 . & & 1 & & & & 2. & & 2. & & 3 & & 3 & & 4 & \\
\hline HRT (day) & 35.7 & 37.2 & 26.8 & 28.6 & 21.4 & 23.2 & 17.9 & 19.5 & 15.3 & 15.2 & 13.4 & 14.8 & 8.2 & 13.2 & 7.4 & 11.9 \\
\hline
\end{tabular}




\subsection{Stable Isotope Analysis}

The carbon isotope composition of the solid waste products (filter cake and bagasse) were measured in a continuous flow system consisting of an elemental analyser (Euro EA, HEKAtech $\mathrm{GmbH}$, Wegberg, Germany) connected to an isotope ratio mass spectrometer (Finnigan MAT 253, Thermofinnigan, Bremen, Germany).

Biogas from the reactor headspace was sampled with a syringe at the same time as digestate was sampled. Twenty $\mathrm{mL}$ biogas was transferred and stored in gas-tight pre-evacuated vials until further analysis. Isotope measurements were performed as described by Feisthauer, et al. [37]. Briefly, an isotope ratio mass spectrometry system (Finnigan MAT 253, Thermofinnigan, Bremen, Germany) was coupled to a gas chromatograph (HP 6890 Series, Agilent Technology, Santa Clara, CA, USA) either via a combustion device for carbon analysis or via a pyrolysis unit for hydrogen analysis. Fifty $\mu \mathrm{L}$ of biogas sample from the vials were injected into a helium carrying tube at the split ratio of 1:50 for carbon and 1:5 for hydrogen analysis.

\section{Conclusions}

Strong dynamics of community structure and pathway shifts in methanogens were observed by molecular and stable isotope fingerprinting during gradual increase of OLR. The overloading effect in both digestion set-ups was observed beginning at an OLR of $2.5 \mathrm{~g}_{\mathrm{vs}} \cdot \mathrm{L}^{-1} \cdot \mathrm{day}^{-1}$ from the increase of the propionate-to-acetate ratio. However, the co-digestion processes suffered process failure earlier (at OLR 3.0) than mono-digestion (at OLR 3.5). Until process-overload Methanosarcina became gradually predominant, shifting the methanogenic pathway towards aceticlastic. The change towards hydrogenotrophic methanogenesis during reactor overload might be taken as an indicator for process failure. Monitoring of the methanogenic pathways by stable isotope composition of biogas can be an excellent tool to control and predict process failure.

\section{Supplementary Materials}

Supplementary materials can be found at http://www.mdpi.com/1422-0067/16/10/23210/s1.

\section{Acknowledgments}

The Brazilian scientific mobility program, Science without Borders (Pt.: Ciência sem Fronteiras) is the funding agency for the scholarship grants of Athaydes Francisco Leite and Leandro Janke. We would like to thank for the technical support of Bärbel Haase and Birke Brumme with the analytics, Ute Lohse with the molecular analyses and Ursula Günther with the isotope measurements. The research was partially financed by the i-NoPa project: Sustainable bioeconomy in Brazil: Bioenergy from biogas using various types of waste substrates from the Brazilian bioethanol industry.

\section{Author Contributions}

Designed the experiments: Athaydes Francisco Leite, Marcell Nikolausz and Leandro Janke; Performed the experiments: Athaydes Francisco Leite, Leandro Janke and Zuopeng Lv. Analyzed and 
interpreted the data: Athaydes Francisco Leite, Marcell Nikolausz and Hans-Hermann Richnow; Supervised the study: Marcell Nikolausz and Hauke Harms; Wrote the paper: Athaydes Francisco Leite.

\section{Conflicts of Interest}

The authors declare no conflict of interest.

\section{References}

1. Leite, A.F.; Janke, L.; Harms, H.; Zang, J.W.; Fonseca-Zang, W.A.; Stinner, W.; Nikolausz, M. Assessment of the variations in characteristics and methane potential of major waste products from the brazilian bioethanol industry along an operating season. Energy Fuels 2015, 29, $4022-4029$.

2. Janke, L.; Leite, A.; Batista, K.; Weinrich, S.; Strauber, H.; Nikolausz, M.; Nelles, M.; Stinner, W. Optimization of hydrolysis and volatile fatty acids production from sugarcane filter cake: Effects of urea supplementation and sodium hydroxide pretreatment. Bioresour. Technol. 2015, doi:10.1016/j.biortech.2015.07.117.

3. Janke, L.; Leite, A.; Wedwitschka, H.; Schmidt, T.; Nikolausz, M.; Stinner, W. Biomethane production integrated to the brazilian sugarcane industry: The case study of são paulo state; In Proceedings of the 22nd European Biomass Conference and Exhibition, Hamburg, Germany, December 2014; pp. 1295-1299.

4. Janke, L.; Leite, A.; Nikolausz, M.; Schmidt, T.; Liebetrau, J.; Nelles, M.; Stinner, W. Biogas production from sugarcane waste: Assessment on kinetic challenges for process designing. Int. J. Mol. Sci. 2015, 16, 20685-20703.

5. Nikolausz, M.; Walter, R.F.; Strauber, H.; Liebetrau, J.; Schmidt, T.; Kleinsteuber, S.; Bratfisch, F.; Gunther, U.; Richnow, H.H. Evaluation of stable isotope fingerprinting techniques for the assessment of the predominant methanogenic pathways in anaerobic digesters. Appl. Microbiol. Biotechnol. 2013, 97, 2251-2262.

6. Weiland, P. Biogas production: Current state and perspectives. Appl. Microbiol. Biotechnol. 2010, $85,849-860$.

7. Demirel, B.; Scherer, P. The roles of acetotrophic and hydrogenotrophic methanogens during anaerobic conversion of biomass to methane: A review. Rev. Environ. Sci. Biol. Technol. 2008, 7 , 173-190.

8. Chen, Y.; Cheng, J.J.; Creamer, K.S. Inhibition of anaerobic digestion process: A review. Bioresour. Technol. 2008, 99, 4044-4064.

9. Briones, A.; Raskin, L. Diversity and dynamics of microbial communities in engineered environments and their implications for process stability. Curr. Opin. Biotechnol. 2003, 14, 270-276.

10. Karakashev, D.; Batstone, D.J.; Angelidaki, I. Influence of environmental conditions on methanogenic compositions in anaerobic biogas reactors. Appl. Environ. Microbiol. 2005, 71, $331-338$. 
11. Lucas, R.; Kuchenbuch, A.; Fetzer, I.; Harms, H.; Kleinsteuber, S. Long-term monitoring reveals stable and remarkably similar microbial communities in parallel full-scale biogas reactors digesting energy crops. FEMS Microbiol. Ecol. 2015, 91, doi:10.1093/femsec/fiv004.

12. Blume, F.; Bergmann, I.; Nettmann, E.; Schelle, H.; Rehde, G.; Mundt, K.; Klocke, M. Methanogenic population dynamics during semi-continuous biogas fermentation and acidification by overloading. J. Appl. Microbiol. 2010, 109, 441-450.

13. Franke-Whittle, I.H.; Walter, A.; Ebner, C.; Insam, H. Investigation into the effect of high concentrations of volatile fatty acids in anaerobic digestion on methanogenic communities. Waste Manag. 2014, 34, 2080-2089.

14. Marchaim, U.; Krause, C. Propionic to acetic acid ratios in overloaded anaerobic digestion. Bioresour. Technol. 1993, 43, 195-203.

15. Steinberg, L.M.; Regan, J.M. Phylogenetic comparison of the methanogenic communities from an acidic, oligotrophic fen and an anaerobic digester treating municipal wastewater sludge. Appl. Environ. Microbiol. 2008, 74, 6663-6671.

16. Talbot, G.; Topp, E.; Palin, M.; Masse, D. Evaluation of molecular methods used for establishing the interactions and functions of microorganisms in anaerobic bioreactors. Water Res. 2008, 42, 513-537.

17. Chidthaisong, A.; Chin, K.-J.; Valentine, D.L.; Tyler, S.C. A comparison of isotope fractionation of carbon and hydrogen from paddy field rice roots and soil bacterial enrichments during $\mathrm{CO}_{2} / \mathrm{H}_{2}$ methanogenesis. Geochim. Cosmochim. Acta 2002, 66, 983-995.

18. Lv, Z.; Leite, A.F.; Harms, H.; Richnow, H.H.; Liebetrau, J.; Nikolausz, M. Influences of the substrate feeding regime on methanogenic activity in biogas reactors approached by molecular and stable isotope methods. Anaerobe 2014, 29, 91-99.

19. Lv, Z.; Hu, M.; Harms, H.; Richnow, H.H.; Liebetrau, J.; Nikolausz, M. Stable isotope composition of biogas allows early warning of complete process failure as a result of ammonia inhibition in anaerobic digesters. Bioresour. Technol. 2014, 167, 251-259.

20. Keppler, F.; Laukenmann, S.; Rinne, J.; Heuwinkel, H.; Greule, M.; Whiticar, M.; Lelieveld, J. Measurements of $13 \mathrm{C} / 12 \mathrm{C}$ methane from anaerobic digesters: Comparison of optical spectrometry with continuous-flow isotope ratio mass spectrometry. Environ. Sci. Technol. 2010, 44, 5067-5073.

21. Nielsen, H.; Uellendahl, H.; Ahring, B. Regulation and optimization of the biogas process: Propionate as a key parameter. Biomass Bioenerg. 2007, 31, 820-830.

22. Prochazka, J.; Dolejs, P.; Maca, J.; Dohanyos, M. Stability and inhibition of anaerobic processes caused by insufficiency or excess of ammonia nitrogen. Appl. Microbiol. Biotechnol. 2012, 93, 439-447.

23. Jenkins, D.; Richard, M.G.; Daigger, G.T. Manual on the Causes and Control of Activated Sludge Bulking, Foaming, and Other Solids Separation Problems; IWA Publishing: London, UK, 2003; pp. 131-161.

24. Zinder, S. Physiological ecology of methanogens. In Methanogenesis; Ferry, J., Ed.; Springer: New York, NY, USA, 1993; pp. 128-206. 
25. Griffin, M.E.; McMahon, K.D.; Mackie, R.I.; Raskin, L. Methanogenic population dynamics during start-up of anaerobic digesters treating municipal solid waste and biosolids. Biotechnol. Bioeng. 1998, 57, 342-355.

26. Yu, Y.; Kim, J.; Hwang, S. Use of real-time PCR for group-specific quantification of aceticlastic methanogens in anaerobic processes: Population dynamics and community structures. Biotechnol. Bioeng. 2006, 93, 424-433.

27. Chen, S.; He, Q. Persistence of methanosaeta populations in anaerobic digestion during process instability. J. Ind. Microbiol. Biotechnol. 2015, 42, 1129-1137.

28. Yashiro, Y.; Sakai, S.; Ehara, M.; Miyazaki, M.; Yamaguchi, T.; Imachi, H. Methanoregula formicica sp. nov., a methane-producing archaeon isolated from methanogenic sludge. Int. J. Syst. Evol. Microbiol. 2011, 61, 53-59.

29. O’Leary, M.H. Carbon isotopes in photosysnthesis. BioScience 1988, 38, 328-336.

30. Conrad, R. Quantification of methanogenic pathways using stable carbon isotopic signatures: A review and a proposal. Org. Geochem. 2005, 36, 739-752.

31. Galand, P.E.; Yrjälä, K.; Conrad, R. Stable carbon isotope fractionation during methanogenesis in three boreal peatland ecosystems. Biogeosciences 2010, 7, 3893-3900.

32. Whiticar, M.J.; Faber, E.; Schoell, M. Biogenic methane formation in marine and freshwater environments: $\mathrm{CO}_{2}$ reduction vs. Acetate fermentation-Isotope evidence. Geochim. Cosmochim. Acta 1986, 50, 693-709.

33. Schmidt, T.; Ziganshin, A.M.; Nikolausz, M.; Scholwin, F.; Nelles, M.; Kleinsteuber, S.; Pröter, J. Effects of the reduction of the hydraulic retention time to 1.5 days at constant organic loading in CSTR, ASBR, and fixed-bed reactors-Performance and methanogenic community composition. Biomass Bioenerg. 2014, 69, 241-248.

34. Tauber, T.; Berta, B.; Szabo, Z.; Kovacs, J.; Marialigeti, K.; Toth, E.M. A simple and novel volumetric method to metre low gas flows from laboratory-scale bioreactors and its application on laboratory sludge digesters. Appl. Microbiol. Biotechnol. 2011, 90, 1453-1461.

35. Ziganshin, A.M.; Schmidt, T.; Scholwin, F.; Il'inskaya, O.N.; Harms, H.; Kleinsteuber, S. Bacteria and archaea involved in anaerobic digestion of distillers grains with solubles. Appl. Microbiol. Biotechnol. 2011, 89, 2039-2052.

36. Sträuber, H.; Schröder, M.; Kleinsteuber, S. Metabolic and microbial community dynamics during the hydrolytic and acidogenic fermentation in a leach-bed process. Energy Sustain. Soc. 2012, 2 , 13, doi:10.1186/2192-0567-2-13.

37. Feisthauer, S.; Siegert, M.; Seidel, M.; Richnow, H.H.; Zengler, K.; Gründger, F.; Krüger, M. Isotopic fingerprinting of methane and $\mathrm{CO}_{2}$ formation from aliphatic and aromatic hydrocarbons. Org. Geochem. 2010, 41, 482-490.

(C) 2015 by the authors; licensee MDPI, Basel, Switzerland. This article is an open access article distributed under the terms and conditions of the Creative Commons Attribution license (http://creativecommons.org/licenses/by/4.0/). 